\title{
THEMATIC PROGRESSION ANALYSIS IN INDONESIAN EFL STUDENTS' THESIS ABSTRACTS
}

\author{
Rika Vennia Rahmawati \\ Department of English Education, Indonesia University of Education, Indonesia \\ Email: venniarika@gmail.com \\ Eri Kurniawan \\ Department of English Education, Indonesia University of Education, Indonesia \\ Email: eri_kurniawan@upi.edu
}

APA Citation: Rahmawati, R. V. \& Kurniawan, E. (2015). Thematic progression analysis in students' thesis abstracts. Indonesian EFL Journal, 1(1). 81-87

\begin{abstract}
This study examines thematic progression in thesis abstracts written by English students in Indonesia University of Education. This study employs a descriptive qualitative method since it attempts to describe and analyze textual data accurately. The data for this study come from repository.upi.edu. Five undergraduate students' thesis abstracts were downloaded from the website published in 2014. After gathering the data, a thematic progression theory proposed by Fries (2002) is employed to analyze the data. Findings show that constant theme is the type of thematic progression that is mostly used the thesis abstracts by $52.64 \%$. The linear theme and split rheme thematic progression pattern are also found in the abstracts. However, split rheme is found only once. Among the problems the students have probably encountered are how to write a coherent abstract and to create an appropriate logical relation among sentences in their writing. This study concludes that the students' thesis abstracts mostly use constant theme pattern, which suggests their writing is not quite well-arranged. Since an abstract should be written in more or less 200 words and it should represent the important information of the research, students may be confused as to how to summarize their research into 200 words.
\end{abstract}

Keywords: thesis abstracts, thematic progression, English students

\section{INTRODUCTION}

Successful communication must revolve around transferring meanings, which are tied in grammatical structure. Grammar can be defined as a combination of linguistics unit, which produces sentences in the language (Richards and Schmidt, 2002). Grammar does not only focus on grammatical selection but also on patterns of grammar and vocabulary that are combined to tie meanings in the text to make it cohesive and coherent. The way in which cohesive and coherent texts are created through resources such as patterns of cohesion is understood as unity of texture (Paltridge, 2006). Among the elements that contribute to the texture of a text is thematic structure. Thematic structure deals with the organization of a clause or an utterance which consists of theme and rheme to form a message (Sharndarma and Panamah, 2013).
The theme and rheme relationship contributes to the flow of information in the text.

Theme can be understood as the element which serves as point of departure of the message and rheme as the remainder of the message in which the theme is developed (Halliday and Mathiesssen, 2004). Theme can be identified as the elements which come first in a clause (Gerot and Wignell, 1994). Theme indicates what the text is about. There are three catagories of theme; ideational or topical theme, textual theme, and interpersonal theme (Gerot and Wignell, 1994).

The idea of theme and rheme furthermore leads to the analysis of thematic progression or method of development of texts (Fries, 2002, cited in Paltridge, 2006). According to Paltridge (2006), thematic 
progression refers to "the way in which the theme of a clause may pick up, or repeat, a meaning from a preceding theme or rheme". The thematic progression is the key way to create information flow in a text. According to Fries (2002 as cited in Paltridge, 2006), there are three forms of Thematic Progression; constant theme or theme reiteration, zig-zag or linear theme, and multiple theme or split rheme.

The first pattern of thematic progression is constant theme. Constant theme or theme reiteration refers to the patterns in which theme 1 is repeated in the beginning of next clause. It indicates that each clause has information to discuss. For example:

Table 1. Theme and rheme: Constant theme (based on Cornbleet and Carter, 2001 as cited in Paltridge, 2006)

\begin{tabular}{ll}
\hline Theme & Rheme \\
\hline Text & can be used for both spoken and written language. \\
It & usually refers to a stretch, an extract or complete piece of writing or speech. \\
\hline
\end{tabular}

Figure 1

Thematic Progression: Constant theme based on Table 1 (Paltridge, 2006).

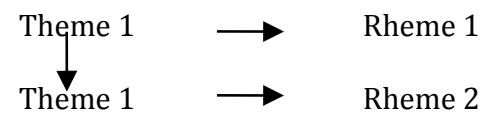

The second pattern of thematic progression is linear theme. Linear theme or zig-zag theme refers to the rheme 1 which is repeated as the theme 2 in the next clause. For example:

Table 2

Theme and rheme : Zig-zag/linear theme (based on Knapp and Walkins, 2005, as cited in Paltridge, 2006)

\begin{tabular}{ll}
\hline Theme & Rheme \\
\hline The term 'modality' & $\begin{array}{l}\text { describes a range of grammatical resources used to express probability or obligation. } \\
\text { is used in speech, speech, especially when wanting to get things done such as 'You should } \\
\text { keep your room tidy'. }\end{array}$ \\
\hline
\end{tabular}

Figure 2

Thematic Progression: Zig-zag/linear theme based on Table 2 (Paltridge, 2006).

Theme 1

Theme 2

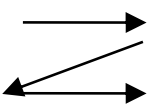

Rheme 1

Rheme 2

The last pattern of thematic progression is split rheme or multiple theme. In split rheme or multiple theme, a rheme may include some different information which may be taken up as theme in some subsequent clauses (Paltridge, 2006). For example:

Table 3

Theme and rheme: A multiple / split rheme pattern (based on Nesbitt et al, 1990, cited in Paltridge, 2006).

\begin{tabular}{ll}
\hline Theme & Rheme \\
\hline When Japanese people & $\begin{array}{l}\text { write their language, } \\
\text { use a combination of two separate alphabets as well as ideograms borrowed from } \\
\text { Chinese. }\end{array}$ \\
$\begin{array}{l}\text { The two alphabets } \\
\text { The Chinese ideograms } \\
\text { are called kanji. }\end{array}$ \\
$\begin{array}{l}\text { Hiragana } \\
\text { Katakana }\end{array}$ & $\begin{array}{l}\text { represents the } 46 \text { basic sounds that are made in the Japanese language. } \\
\text { represts the same sounds as hiragana. }\end{array}$ \\
\hline
\end{tabular}


Figure 3

Thematic progression: Multiple theme / split rheme based on Table 3 (Paltridge, 2006).

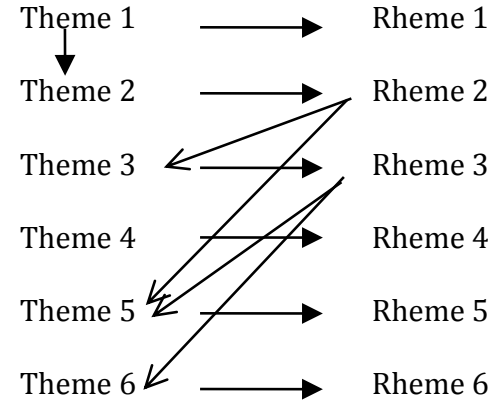

Thematic Progression theory is mostly employed to analyze texts in academic field. By employing Thematic Progression theory, Arunsirot's (2013) study reveals that there are five problems of theme found in students' writing which are the problem of empty theme, the problem of the brand new theme, the problem of overuse of constant progression, the problem of empty rheme, and the problem of confusing selection of textual theme. To improve students' writing skills, Thematic Progression analysis can be employed in teaching writing (Yang, 2008). Besides, textual theme and its types can be effectively applied in classrooms to help students in writings (Ebrahimi \& Ebrahimi, 2012). Students' knowledge background also influences their writings. According to a study conducted by North (2005), students with arts backgrounds obtained higher marks for their assignments than students with science backgrounds. Moreover, a study conducted by Khedri (2012) which analyzes Thematic Progression in English and Persian academic texts reveals that there are significant differences between the languages in focus concerning how information are introduced in texts especially in case of linear and constant patterns.

The purpose of thematic progression is to create a well-structured text. A wellstructured text is indicated through the unity and connectedness between individual sentences that relate to each other. Therefore, this present study primarily examines thematic progression pattern in thesis abstracts written by English students in Indonesia University of Education by employing the thematic progression theory proposed by Fries (2002) to explore how their ideas are constructed in writing their abstracts.

\section{METHOD}

This study employs a descriptive qualitative methodology by using thematic progression theory proposed by Fries (2002, as cited in Paltridge, 2006) since this study attempts to investigate the thematic progression patterns found in five thesis abstracts written by undergraduate students whose major is English Education in Indonesia University of Education in order to see how their ideas are constructed. However, the study also employs some quantitative measurement in calculating the number of each occurrence of thematic progression pattern found in the students' thesis abstracts.

The abstracts are collected from online library of Indonesia University of Education, repository.upi.edu. Five abstracts are chosen randomly which were published in 2014.

After gathering the data, thematic progression theory proposed by Fries (2002, as cited in Paltridge, 2006) is employed to analyze the data by:

1. Close-reading the downloaded abstracts.

2. Breaking down the abstracts into clauses

3. Placing the clauses into table format to make the process of the analysis easier and clearer

4. Determining the theme and rheme

5. Classifying the thematic progression pattern, whether it is constant, linear, or multiple theme.

6. Calculating the occurence of each type of thematic progression patterns found in the abstracts. 
7. Interpreting the findings to draw a conclusion of how English students' of Indonesia University of education present their ideas in their thesis abstracts.

\section{FINDINGS AND DISCUSSION}

The following tables show the distribution of thematic progression patterns found in students' thesis abstract and its percentage as well.

Table 4. The distribution of thematic progression pattern

\begin{tabular}{llllll}
\hline TP pattern/samples & A & B & C & D & E \\
\hline Constant theme & 3 & 2 & 1 & 2 & 2 \\
Linear theme & 1 & 3 & 1 & 1 & 2 \\
Multiple theme & 1 & 0 & 0 & 0 & 0 \\
\hline
\end{tabular}

Table 5. The percentage of thematic progression pattern.

\begin{tabular}{lll}
\hline TP Patterns & Total & Percentage \\
\hline Constant theme & 10 & $52.64 \%$ \\
Linear theme & 8 & $42.10 \%$ \\
Multiple theme & 1 & $5.26 \%$ \\
\hline
\end{tabular}

From the tables above, it can be seen that thesis abstracts written by five English students in Indonesia University of Education mostly use constant theme by $52.64 \%$. Eight linear themes are also found in the abstracts and there is only one multiple theme found.
The use of constant theme and linear theme pattern in most of the abstracts used as the samples in this study may indicate the discontinuity of information in the texts.

The samples of data are presented below:

Table 6. Theme and rheme based on data $C$

\begin{tabular}{|c|c|}
\hline Theme & Rheme \\
\hline This study & $\begin{array}{l}\text { presents the analysis of how the national mass media deliver their ideological } \\
\text { point of view to the readers in their online articles regarding a political issue in } \\
\text { Joko Widodo and Basuki Tjahja Purnama first } 100 \text { days of office. }\end{array}$ \\
\hline It & was aimed at investigating the way social actors are represented in the text \\
\hline and to uncover & the ideologies underlying the representation. \\
\hline The data & $\begin{array}{l}\text { were obtained from ten online articles from different nationwide media } \\
\text { published in } 22 \text { January } 2013 \text {. }\end{array}$ \\
\hline A qualitative method & was employed to analyse the selected data. \\
\hline The data & $\begin{array}{l}\text { were analysed based on the sociosemantic approach proposed by Van Leeuwen } \\
\text { (2008). }\end{array}$ \\
\hline The findings & showed \\
\hline $\begin{array}{l}\text { that Jokowi as the governor of } \\
\text { Jakarta }\end{array}$ & was dominated the occurrences as an active participant. \\
\hline Moreover, different impression & was shown \\
\hline where the active roles & were always associated with Jokowi \\
\hline and the passive roles & were always associated with Jakarta. \\
\hline The findings also & $\begin{array}{l}\text { revealed that the possible ideologies that can be inferred from the representation } \\
\text { were democracy and Jokowi as the "city rescuer." }\end{array}$ \\
\hline
\end{tabular}

Thematic progression pattern based on Table 6

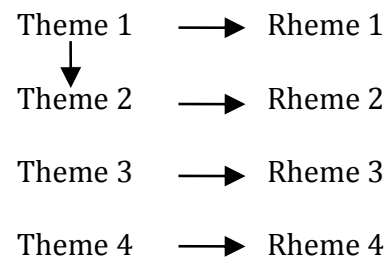




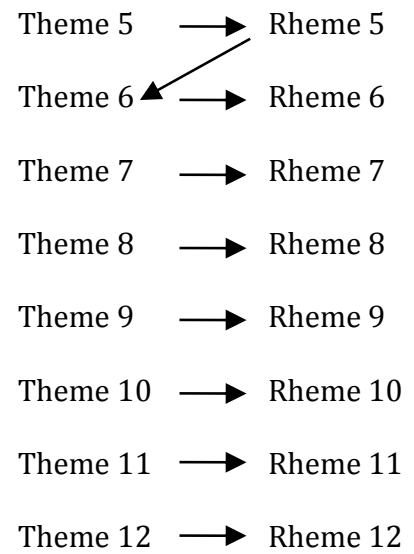

From the analysis above, it can be seen that the student uses one constant theme and one linear theme in the abstract. The progress from theme 1 to theme 2 is called constant theme because theme 1 is repeated in theme 2 . What is being told from rheme 5 is repeated in theme 6 , which makes this progress called linear theme. However, most of the themes in the text have no pattern. It means that the relation between themes is not actually found. This condition may be because the student wants to add new information in the text and has no idea how to make a relation between the clauses.

Table 7. Another example of theme and rheme analysis

\begin{tabular}{ll}
\hline Theme & Rheme \\
\hline This Paper & $\begin{array}{l}\text { Entitled "A Semiotic Analysis: The Severity of Mount Merapi Eruption Portrayed } \\
\text { on Kemal Jufri's Photos as The 2nd Prize Stories Winner of World Press Photo". }\end{array}$ \\
\hline It & $\begin{array}{l}\text { is aimed to uncover the meaning behind the photographs and to discover } \\
\text { symbols, indexes and modes that appear in the photo stories. }\end{array}$ \\
\hline The study & is qualitative which utilizes Eco's (1994) Hermetic drift theory. \\
\hline The theory & $\begin{array}{l}\text { mainly focuses on the meaning of a symbol which not only has one meaning, but } \\
\text { two or more meaning }\end{array}$ \\
\hline if the symbol & is put in a different context. \\
\hline The main data & are 12 photographs \\
\hline which & were used in the photo stories taken from www.wordpressphoto.org \\
\hline The study & revealed the Juffri's photo stories about the disaster of Mt. Merapi eruption. \\
\hline The symbols, indexes and & signify the damages, losses, death, and suffering of the people near Mt. Merapi, \\
modes in the photo stories & which directly got the worst effect of the disaster. \\
\hline The photo story also & portrays collectiveness of Indonesian people to help the victims of the disaster. \\
\hline
\end{tabular}

Figure 5. Thematic progression pattern based on Table 7.

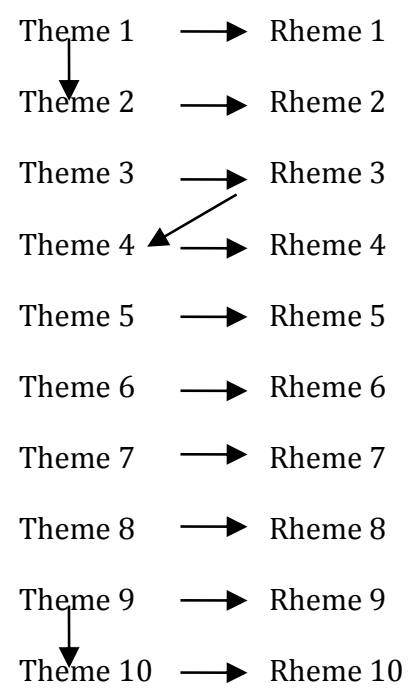


In the sample data presented above, there are two constant themes and one linear theme. Theme 1 is related to theme 2 which means that it has a contant theme pattern. Theme 9 is related to theme 10 which indicates the constant theme pattern as well. Besides, what is written in rheme 3 is used in theme 4 which means it has a linear theme. Just like the analysis in data $\mathrm{C}$, most of the theme in the abstract has no pattern. It means that this abstract is not really hang together.

However, there is one sample in which a multiple theme or split rheme is found. The sample is presented below.

Table 8. Theme and rheme based on data $A$

\begin{tabular}{ll}
\hline Theme & Rheme \\
\hline This paper & $\begin{array}{l}\text { entitled An Analysis of Themes in "The Magic"and Its Indonesian Translation (A } \\
\text { Systemic Functional Grammar Approach) aims to find out the types of Theme and } \\
\text { Thematic Progression in the original version and the translated version of The } \\
\text { Magic and Themes realization in the Indonesian translated version. }\end{array}$ \\
\hline This study & employed a descriptive qualitative method especially textual analysis. \\
\hline The present study & $\begin{array}{l}\text { adopted Halliday's (1994) theory of Systemic Functional Grammar as a tool to } \\
\text { analyze the Themes used in the texts and also Eggins' (2004) theory of thematic } \\
\text { progression. }\end{array}$ \\
\hline The study & found \\
\hline $\begin{array}{l}\text { That in the source text and in } \\
\text { the target text, there }\end{array}$ & are three types of Theme found out. \\
\hline Those & are Topical Theme, Textual Theme and Interpersonal Theme. \\
\hline $\begin{array}{l}\text { Moreover, the types of } \\
\text { Thematic Progression in source } \\
\text { text and target text }\end{array}$ & show the same pattern. \\
\hline The finding also & shows \\
\hline That there & are four pattern of Theme realization in translation text. \\
\hline The first pattern, the Themes & are translated like the original. \\
\hline $\begin{array}{l}\text { The second pattern, part of } \\
\text { Theme }\end{array}$ & is ellipted. \\
\hline The third pattern, there Rheme & are some words from translated as Theme. \\
\hline The last is the Themes & are shifted in the process of translation. \\
\hline The realization of Theme also & does not affect the Thematic Progression. \\
\hline
\end{tabular}

Figure 6. Thematic progression pattern based on Table 7

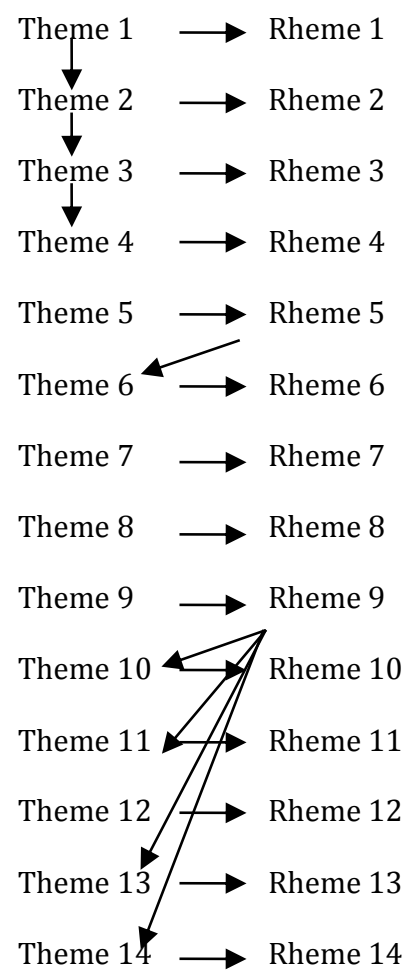


From the analysis above, it can be seen that Rheme 9 presents information in the subsequent themes, in Theme 10, Theme 11, Theme 12, and Theme 13.

Since most of the samples seem not really well arranged due to their lack of thematic patterns, it may indicate the difficulties that they face in writing abstracts. The problem that they probably find is that how to write a coherent abstract and to create an appropriate logical relation between sentences in their writing. The students may also find the problem in writing abstract because of the constraint in terms of numbers of words in writing an abstract. An abstract generally should be written in more or less 200 words and it should represent the important information or key elements of the research. In light of that, students may be confused as to how to summarize or condense their research into 200 words so that their abstract appears to lack integration.

\section{CONCLUSION}

The study has found that constant theme is the type of thematic progression pattern that mostly used by the students in writing their abstracts (52.64\%). Linear theme $(42.10 \%)$ and multiple theme (5.26\%) are also found in the abstracts. The overuse of constant theme and lack of linear and multiple theme used in the abstracts may indicate that the abstracts are not really hang together. This problem could be attributed to the fact that the students may find it difficult to condense their research into a 200 hundred word-kind of abstract.

\section{References}

Arunsirot, S. (2013). An analysis of textual metafunction in Thai EFL. Novitas-ROYAL (Research on Youth and Language). 7(2), 160-174.

Ebrahimi, S. F., \& Ebrahimi, S. J. (2012). Factuality in undergraduate students' writings. International Journal of English and Education.

Gerot, L., \& Wignell, P. (1994). Making sense of functional grammar. An introductory work book. Sydney: Gerd Stabler.

Halliday, M.A.K., Mathiessen, C.M.I.M. (2004). An introduction to functional grammar. (3rd Ed). London: Edward Arnold

Khedri, M. (2012). The flow of information in English and Persian academic texts. Journal of Language Teaching and Research, 3(6), 1175-1179.

North, S (2005). Disciplinary variation in the use of theme in undergraduate essays. Journal of Applied Linguistics, 26(3), 431-452.

Paltridge, B. (2006). Discourse analysis. An introduction. London: Continuum.

Richards, J. C. \& Schmidt, R. (2002). Longman dictionary of language teaching and applied linguistics (3rd ed.). Harlow: Longman.

Yang, X. (2008). Thematic Progression Analysis in Teaching Explanation Writing. CCSE English Language Teaching, 1(1), 29-33. 